\title{
Editorial
}

\section{Responding to Child Maltreatment, Incarcerated Mothers and Care Descriptions at Work}

by

Kjersti Ørvig

Associate Professor, PhD

Department of Social Studies, University of Stavanger

Norway

E-mail: kjersti.orvig@uis.no

DOI: https://doi.org/10.31265/jcsw.v14.i2.245

\section{() (1) (-)}

This work is licensed under a Creative Commons Attribution-ShareAlike 4.0 International License. 


\section{Dear reader:}

The Journal of Comparative Social Work (JCSW) is an important journal for promoting and disseminating Social Work. Since the first edition in 2006, the aim of the journal has been to draw attention to the field of comparative social work. The JCSW considers this important in order to help shed light on global challenges in social work, and to increase our understanding of the contextual nature of social work practice (Oltedal, 2006). This is demonstrated by the three articles in this issue.

Child maltreatment is a major topic of concern in European countries. In their article: Responding to Child Maltreatment: Comparison between School Social Work in Finland and Germany, Kathrin Franziska Beck and Riitta Vornanen compare the response of Finnish and German school social workers to a case vignette, thus indicating multiple forms of child maltreatment. The findings reveal that Finnish school social workers would inform the child protection services and the police directly after information regarding suspected maltreatment had been verified, whereas the German participants would seek professional advice and carry out a risk assessment. However, despite the fundamental differences between these approaches, both are in line with national legislation.

The voices of women inmates remain largely absent from research into correctionalinstitutions, making them an invisible, under-researched and critical population group. This is particularly true of African women inmates who are mothers and are accompanied by their children in correctional institutions. Eden Begna Gobena's and Sarah Hean's article: The Experience of Incarcerated Mothers Living in a Correctional-Institution with their Children In Ethiopia, addresses these shortfalls and assumptions. The article is aimed at exploring the inmates' experiences of motherhood, the challenges they and their children face and their experiences of the services and support programmers available.

The results of in-depth interviews with incarcerated mothers demonstrate that they perceive themselves as victims of societal discrimination, abuse and structural injustice, both before and after incarceration. 
The ageing and greying population is becoming an increasing concern for contemporary societies in OECD countries and beyond. The world's share of older people (aged 60 years + ) is predicted to increase from 11.7\% in 2013 (UN 2013, xii) to $21.1 \%$ by 2050 . The accompanying inevitable increase in the need for health and social care sector resources has prompted governments to focus on increasing service efficiency and sustainability.

The last article by Kjetil G. Lundberg: Care Descriptions at Work: Textual Technologies from the Standpoint of Care Workers, draws on insights from institutional ethnography (IE). It examines care work practices from the standpoint of care workers in care settings in Norway. One type of form that care workers use on a daily basis is individual care descriptions (ICDs). The findings indicate that ICDs contribute to standardizing care work practices related to changes in the cultural and institutional foundation of the welfare state.

\section{A farewell message}

I began the journey as Editor-in-Chief (EIC) of the JCSW in 2015. It has given me an opportunity to read many extraordinary manuscripts and to see their transformation into articles published in the journal. The quality of incoming papers is high, and there have not been many submitted manuscripts rejected in the first review round. It has been a privilege to engage and interact with social work practitioners and scholars, both nationally and internationally.

Please allow me to thank the JCSW editorial team: Solveig Botnen Eide, Hulda Mjøll Gunnarsdottir, Wenche Hovland, Hilde B. Moen, Siv Oltedal, Anne Ryen, Johans Tveit Sandvin and Yan Zhao. As EIC, it has been a great privilege to engage and interact with you.

Many thanks to the editorial board and other reviewers closely involved in the editorial work. Without you, the journal would not exist.

I welcome the new EIC, and I am sure she will move the journal forward. 
Journal of Comparative Social Work 2019/2

\section{References}

Oltedal, S. (2006). Welcome to Journal of Comparative Social Work. Journal of Comparative Social Work 1(1), 1-2. https://doi.org/10.31265/jcsw.v1i1.18 